\title{
Evaluation of a Novel Web-Based Prior Approval Application for Palivizumab Prophylaxis of Respiratory Syncytial Virus in a State Medicaid Program
}

\author{
Kristin Lundeen, PharmD; Trista Pfeiffenberger, PharmD, MS; Julie Jacobson Vann, PhD, MS, RN; \\ Timothy O'Brien, MSc; Charlene Sampson, RPh; and Steven Wegner, MD, JD
}

\begin{abstract}
BACKGROUND: Recent disproportionate increases in use of specialty medications, such as palivizumab (Synagis), compared with steady utilization of traditional medication use, have prompted complex utilization management strategies that require frequent evaluation to facilitate cost-effectiveness while preserving patient access. Clinical criteria utilized by North Carolina (NC) Medicaid for use of palivizumab for respiratory syncytial virus (RSV) prophylaxis are consistent with the most recent guidelines published in the Red Book: Report of the Committee on Infectious Diseases. Prior to the 2011-2012 RSV season, prior approval (PA) requests were submitted by facsimile using the NC Medicaid Synagis PA form. A web-based PA application, which includes automatic approval capability, monthly dose prompts to providers, and a standardized dose projection formula, was developed for the 2011-2012 RSV season.
\end{abstract}

OBJECTIVES: To evaluate the timeliness of palivizumab coverage determination, compliance with palivizumab prophylaxis regimen, and the accuracy of the dose projection formula achieved with this novel web-based PA application for palivizumab prophylaxis in NC Medicaid recipients.

METHODS: A historically controlled retrospective cohort study was conducted in which all palivizumab PA submissions and supporting documentation from the 2010-2011 and 2011-2012 RSV seasons were retrospectively reviewed for date and time of original submission and final coverage determination. Submissions from the 2011-2012 season were also retrospectively reviewed for number of doses approved, number of doses administered, date of administration of each dose, and actual dosage administered. These data were used to evaluate compliance and the projected versus actual beneficiary weight and dose to assess the accuracy of the dose projection formula. Submissions lacking required information were excluded. Time from PA submission to coverage determination was compared between seasons using a 2-sample t-test. The proportion of compliant recipients was calculated based on number of doses received and dosing interval of no more than 35 days. Accuracy of the dose projection formula was evaluated using a paired Student's t-test.

RESULTS: Time to coverage determination decreased overall, on average, by 3.7 days (mean [SD] 8.5 [15.4] vs. 4.8 [9.3]; $P<0.001$ ) for the 20112012 season using the electronic web-based PA application compared with the traditional facsimile-based system used in the 2010-2011 season. Decreased time to coverage determination was observed in both PA requests that required medical review and those that did not. Of all palivizumab recipients who were eligible to receive at least 2 doses $(n=1,233)$, $61.1 \%$ were fully compliant with all doses, and $86.9 \%$ received all but one documentable dose. Of those who received at least 2 documented doses $(n=1,091), 62.8 \%$ received all doses within 35 days of the previous dose. When both definitions of compliance were applied concurrently, $39.3 \%$ of all palivizumab recipients were considered compliant; the mean difference between projected and actual doses was $7.1 \mathrm{mg}$ (95\% Cl: 6.8-7.5;
$P=0.001)$ or $8.6 \%$ (95\% Cl: $8.0-10.0)$. Projected and actual doses did not vary significantly in the sensitivity analysis when excluding entries with $\geq 50 \%$ difference.

CONCLUSIONS: The 2011-2012 web-based PA application improved the timeliness of palivizumab coverage determination compared with the 20102011 facsimile-based system. Observed compliance rates for NC Medicaid recipients were slightly lower than those reported in the literature when defined by number of doses received but were higher when defined by interval between doses. The dose projection formula used for the webbased application appears to be accurate for infants 0-2 years of age.

J Manag Care Pharm. 2013;19(2):115-24

Copyright $\odot 2013$, Academy of Managed Care Pharmacy. All rights reserved.

\section{What is already known about this subject}

- National trend reports indicate that the costs for traditional medications remained nearly flat in 2011, while specialty pharmacy expenditures rose approximately $17 \%$.

- Despite evidence of reduced respiratory syncytial virus (RSV)related hospitalizations, palivizumab has failed to demonstrate consistently positive results in cost-effectiveness studies.

- The American Academy of Pediatrics has published guidelines to target use of palivizumab to infants at highest risk of serious respiratory tract infections associated with RSV.

- Compliance with palivizumab prophylaxis has historically been lower in Medicaid recipients than the commercially insured population.

- Traditional facsimile-based prior approval (PA) systems used for palivizumab may result in significant delay in coverage determination.

- Limited information exists to guide third-party administrators implementing electronic or web-based PA applications.

\section{What this study adds}

- This is the first known web-based PA application for palivizumab in the United States with automatic approval capability.

- Features such as automatic approval and ability to upload supporting documentation are effective at decreasing time to coverage determination. The automatic approval feature eliminated a large portion of delay in coverage determination. 
What this study adds (continued)

- Palivizumab compliance, prompted with alerts from the webbased application, is slightly higher than rates reported in the literature for Medicaid recipients.

- The dose projection formula used by the web-based application appears to accurately predict the dose amount required regardless of age.

$\mathrm{N}$ ational trend reports indicate that the expenditures for traditional medications remained nearly flat in 2011, while specialty pharmacy expenditures rose approximately $17 \%$. This is slightly less than the $19.6 \%$ increase experienced from 2009 to 2010, but it remains notable due to the consistent annual increases of greater than $15 \%$. Within the realm of specialty medications, the 2011 Drug Trend Report published by Express Scripts cited palivizumab (Synagis) as the seventh most costly specialty medication to state Medicaid programs at close to $\$ 4$ per member per year. ${ }^{1}$

Respiratory syncytial virus (RSV) is the leading cause of bronchiolitis in children under 1 year of age and the leading cause of outpatient visits in children under 5 years of age in the United States. ${ }^{2-6}$ Palivizumab, a humanized monoclonal antibody, was approved by the U.S. Food and Drug Administration (FDA) in 1998 to prevent serious lower respiratory tract disease in infants and toddlers considered to be at high risk for RSV disease. The recommended dose is 15 milligrams per kilogram intramuscularly every 28-30 days, beginning at the start of RSV season. ${ }^{7}$

Despite demonstrated efficacy, ${ }^{8}$ conflicting data exist regarding the cost-effectiveness of RSV prophylaxis with palivizumab. ${ }^{9-17}$ The IMpact-RSV trial (1996-1997), which was used to gain FDA approval for the drug, demonstrated that palivizumab reduced RSV hospitalizations by $55 \%$ in high-risk patients who were compliant with the monthly dosing schedule. ${ }^{18}$ The Palivizumab Outcomes Registry yielded no significant association between compliance and RSV hospitalizations when compliance was defined as the number of expected injections, but when defined as receiving all doses within 35 days of the previous injection, compliance was associated with lower odds of RSV hospitalizations. ${ }^{15}$ A retrospective claims review of a managed care organization including commercial and Medicaid beneficiaries found compliance-defined as starting palivizumab on time, receiving the expected number of injections, and no more than a 37-day gap between palivizumab claims-was associated with a decreased proportion of patients with at least 1 respiratory-related emergency room (ER) visit. However, compliance so defined was not associated with a decreased proportion of patients with at least 1 respiratory-related office visit or hospitalization. Median total palivizumab and respiratory-related medical costs were similar for compliant and noncompliant patients. ${ }^{17}$

Medicaid enrollment has been associated with significantly lower compliance rates, as reported in a review of compliance with palivizumab. ${ }^{19}$ In a claims analysis of Florida Medicaid recipients, $67.9 \%$ of Medicaid recipients were considered fully compliant with at least 4 doses of palivizumab, and $41.3 \%$ received at least 5 doses, where 5 doses represented ideal coverage. ${ }^{20}$ Several studies have attempted to identify strategies for increasing compliance through in-home administration programs, telephone calls, and education of caregivers with positive results. ${ }^{15,21-23}$ In the Palivizumab Outcomes Registry, compliance among Medicaid recipients who received palivizumab in the clinic or office setting was reported as $76 \%$ when defined by comparing expected number of doses and actual number of doses received and $61 \%$ when compliance was defined as receipt of all palivizumab doses within 35 days of the previous dose. Compliance rates were higher among recipients who were administered palivizumab in the home for both definitions. Data were collected from the medical record and entered into the registry; the number of doses received and 35-day interval between doses were used as definitions of compliance. ${ }^{15}$

\section{North Carolina Medicaid Palivizumab Prior Authorization History}

While the utilization and total cost of palivizumab to North Carolina (NC) Medicaid has decreased from 2007 to 2011, it remains in the top 25 medications by expenditure, which during the most recent RSV season exceeded $\$ 4$ per member per year. Also, while the cost per unit and cost per claim have risen across that 4-year period, the total cost per recipient has decreased, leading to a concern that adherence may be an increasing problem.

Clinical criteria utilized by the NC Medicaid prior approval (PA) program for the 2010-2011 and 2011-2012 RSV seasons are consistent with the American Academy of Pediatrics (AAP) and Committee of Infectious Diseases recommendations for use of palivizumab published in the Red Book: 2009 Report of the Committee on Infectious Diseases, 28th edition (Figure 1). ${ }^{24}$ These guidelines target infants at highest risk of hospitalization and recommend administration only during peak virus circulation, which is November through March in North Carolina.

Prior to the 2011-2012 season, NC Medicaid providers submitted PA requests and supporting documentation via facsimile. Requests were approved by pharmacy technicians or pharmacists or escalated to medical review, as necessary. This method required paper-based requests to be scanned and shared electronically among reviewers, which may have resulted in substantial delay in coverage determination. Requests were also frequently submitted lacking information necessary to determine medical necessity, which required 


\section{Evaluation of a Novel Web-Based Prior Approval Application for Palivizumab Prophylaxis of Respiratory Syncytial Virus in a State Medicaid Program}

additional attempts to collect missing information. If the provider's request was approved based on clinical criteria, the appropriate number of doses for the entire season was authorized in response to the request.

Following the 2010-2011 palivizumab season, NC Medicaid received reports from providers that unused vials of palivizumab were accumulating at pediatric practices by the end of an RSV season. While this product wastage was presumed in part to be due to poor compliance, it was also thought that on the day of administration a patient's dose may have required fewer vials than were dispensed by the pharmacy. Little is known about compliance with Synagis therapy for NC Medicaid recipients in past seasons because claims data are limited for assessing compliance or the time interval between doses. In a published study that compared the consistency of documentation of palivizumab administration in Medicaid claims and medical records from 28 pediatric practices across North Carolina, injection frequencies matched between the 2 data sources for only $46.2 \%$ of participants, while dates of administration matched in only $1 \%$ of participants. ${ }^{25}$

In response to identified concerns, NC Medicaid developed a web-based PA application for the 2011-2012 RSV season. Several features of the web-based PA application (developed by Infina Connect, Cary, NC) were designed to address challenges from the 2010-2011 RSV season: (a) the application generated an automatic approval if certain criteria were met based on patient information provided; (b) text box selections, dropdown lists, attachment capability, and free text fields prompted providers to submit requests with all information essential to justify medical necessity; (c) the application required individual dose authorizations to be obtained monthly with provider attestation that the previous dose had been administered; (d) vial quantity for coverage was calculated based on established infant and pediatric growth curves; and (e) dose reminder prompts were sent to providers. It was hoped that the features of the web-based application would decrease product wastage along with other benefits, such as increased transparency of the approval and medical review process to providers, decreased time to coverage determination, and allowed measurement of compliance for all palivizumab recipients.

This study evaluated the effect of the electronic PA request application on timeliness of coverage determination when compared with the prior facsimile-based system, the level of palivizumab injection compliance achieved with the implementation of monthly dose prompts to providers, and the accuracy of the weight and dose projection formula utilized within this system.

\section{Methods}

\section{Design}

This historically controlled cohort study retrospectively examined all NC Medicaid PA submissions and supporting documentation for palivizumab for the 2010-2011 and 2011-2012

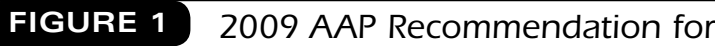 Use of Palivizumab Prophylaxis of RSV Infection}

\begin{tabular}{|c|c|c|}
\hline \multicolumn{3}{|c|}{ Eligible for Up to 5 Doses } \\
\hline $\begin{array}{l}\text { Hemodynamically } \\
\text { Significant Heart } \\
\text { Disease }\end{array}$ & Chronic Lung Disease & Pre-Term \\
\hline \multirow[t]{2}{*}{$<24$ months of age } & \multirow[t]{2}{*}{$\begin{array}{l}<24 \text { months of age } \\
\qquad \text { AND } \\
\text { receiving treatment in } \\
\text { the } 6 \text { months prior to } \\
\text { RSV season }{ }^{\text {a }}\end{array}$} & $\begin{array}{l}<12 \text { months of age } \\
\qquad \text { AND } \\
\text { born at an EGA }<28 \\
\text { weeks } 6 \text { days } \\
\text { OR } \\
\text { significant congenital } \\
\text { abnormalities of the air- } \\
\text { way or a neuromuscular } \\
\text { condition that compro- } \\
\text { mises handling of respi- } \\
\text { ratory tract secretions } \\
\text { AND } \\
\text { born at EGA }<34 \text { weeks } \\
6 \text { days }\end{array}$ \\
\hline & & $\begin{array}{l}<6 \text { months of age } \\
\qquad \text { AND } \\
\text { born at an EGA }<31 \\
\text { weeks } 6 \text { days gestation }\end{array}$ \\
\hline \multicolumn{3}{|c|}{ Eligible for Up to 3 Doses } \\
\hline \multicolumn{3}{|c|}{$\begin{array}{l}<3 \text { months of age } \\
\text { AND } \\
\text { born at EGA of } 32 \text { weeks } 0 \text { days to } 34 \text { weeks } 6 \text { days and has at least } 1 \text { of } 2 \\
\text { risk factors: } \\
\text { - Attends child care } \\
\text { - Has a sibling younger than } 5 \text { years of age in the home } \\
\end{array}$} \\
\hline \multicolumn{3}{|c|}{$\begin{array}{l}\text { Source: Pignotti MS, Indolfe G, Donzelli G. Factors impacting compliance with } \\
\text { palivizumab. }{ }^{23} \\
\text { a } R S V \text { season in North Carolina: November 1-March } 31 . \\
\text { AAP = American Academy of Pediatrics; EGA=estimated gestational age; } \\
\text { RSV = respiratory syncytial virus. }\end{array}$} \\
\hline
\end{tabular}

seasons to compare timeliness of palivizumab coverage determination across the 2 seasons. Evaluation of compliance and the dose projection formula were performed using the 20112012 cohort only. This study was approved by the University of North Carolina at Chapel Hill Institutional Review Board.

\section{Intervention}

The intervention for this study was a novel web-based PA application for palivizumab. The PA application or a medical reviewer may approve up to 5 monthly doses of palivizumab based on clinical criteria (Figure 1). However, in contrast with previous seasons, each monthly dose required individual authorization, which was obtained by attesting to details regarding the administration of the previous dose and providing the patient's most recent weight. Implementation of required individual dose authorizations aimed to (a) decrease product wastage by collecting information about the patient's weight to more accurately project the required vial quantity for the next dose and (b) allow for measurement of compliance. 


\section{FIGURE 2 Sample Selection: Timeliness of Palivizumab Coverage Determination, 2010-2011 Season}

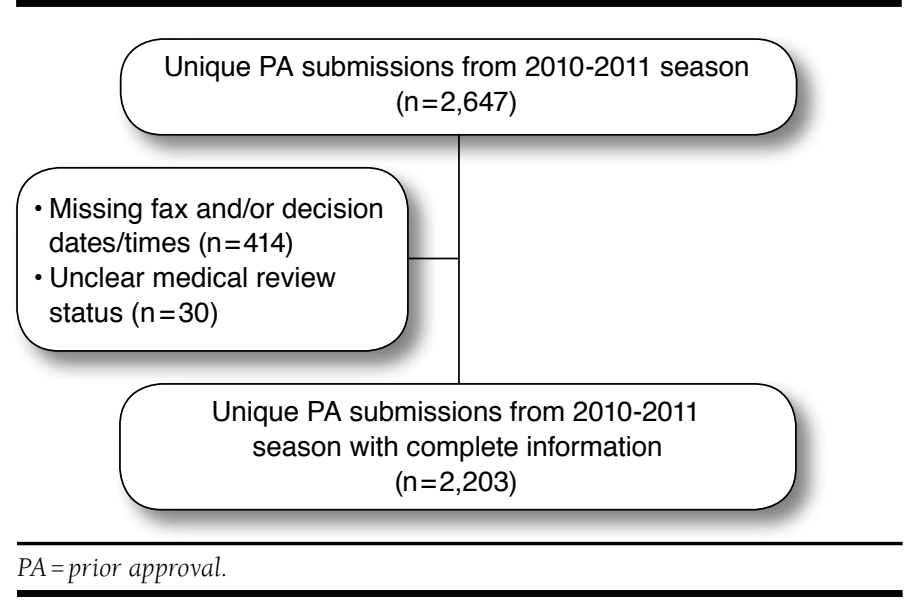

Upon entry of patient information, the application calculated a projected patient weight and corresponding dose 30 days after the date of the last dose. The application then generated an authorization of the appropriate vial size to be dispensed by the pharmacy. The provider faxed this document to the pharmacy as notification of authorization to dispense the next dose. In order to alert providers to potential noncompliance, beginning 40 days after a patient's last dose request date, providers received weekly prompts via e-mail to request the patient's next dose.

\section{Data Sources}

This study used data that were previously collected by NC Medicaid. These data sources included NC Medicaid palivizumab PA request forms, palivuzumab PA decision files, and the web-based PA application. AccessCare personnel previously entered the NC Medicaid palivuzumab PA data from the 20102011 season into a secure electronic database at AccessCare, where the PA files are currently stored. A sample of PA data was checked for reliability of data entry by the primary investigator. Data fields that were selected from the PA data for the 20102011 season included date and time of receipt of the PA request form, date and time of final coverage determination, and level of review. The level of review was defined as standard review by a pharmacist and/or technician versus escalation to medical review. In several cases, multiple PA requests were submitted for the same child; only data from the first submission were collected. Additional data collected only from the 2011-2012 season included total number of doses approved, number of doses provider attested to have been administered, date of palivizumab administration, projected patient weight, actual patient weight, and the amount of each dose administered.

\section{FIGURE 3 Sample Selection: Compliance Analysis}

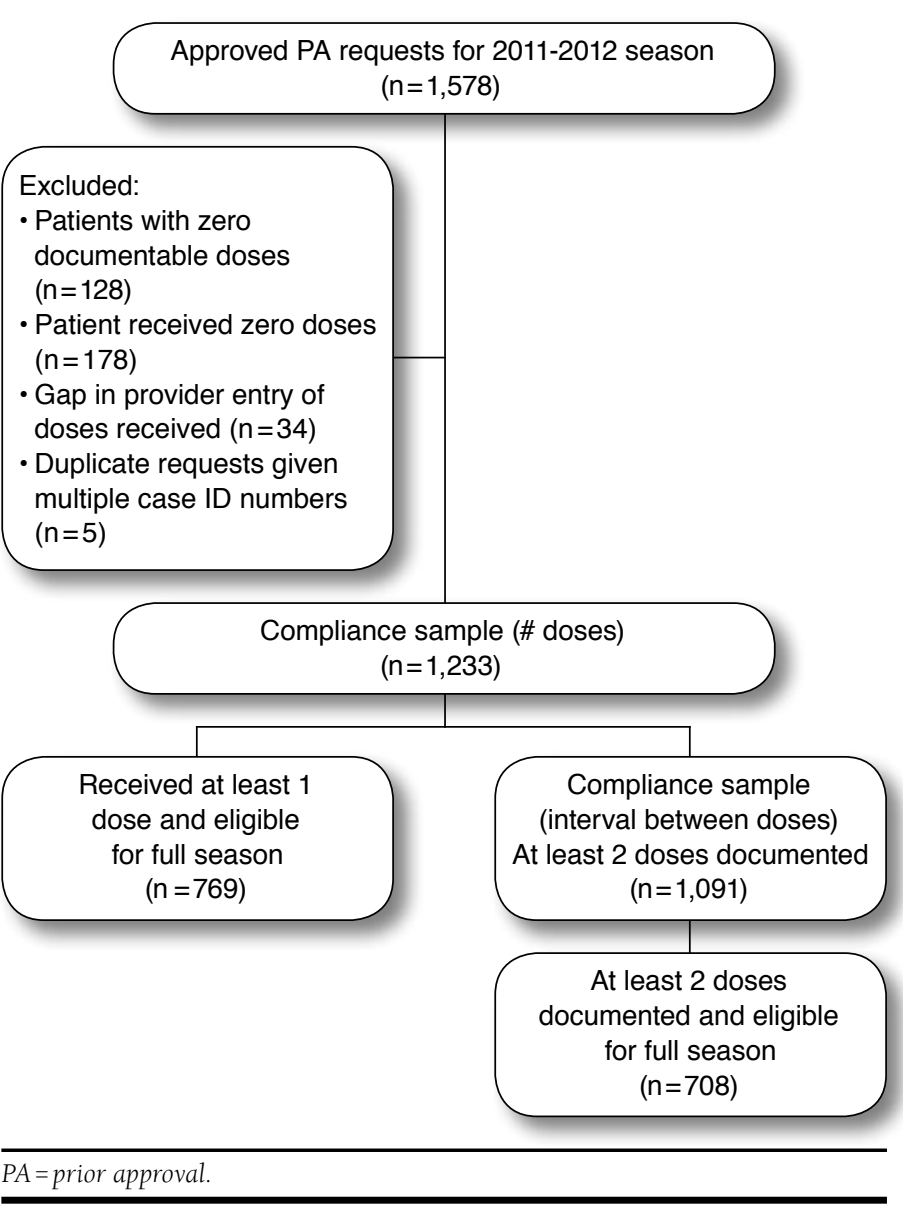

\section{Inclusion and Exclusion Criteria}

Distinct inclusion and exclusion criteria were employed for each major study question.

- Time to palivizumab coverage determination. All unique palivizumab PA requests were included in the analysis for the 2011-2012 season. For the 2010-2011 season, requests (16.8\%) were excluded because of missing fax and/or coverage decision dates or times or unclear medical review status (Figure 2).

- Compliance. All approved palivizumab PA requests for the 2011-2012 season were reviewed for inclusion in the compliance analysis. For analysis of compliance defined by number of doses documented as administered, patients were excluded (21.9\%) if they were not eligible to receive at least 2 doses within the season, if no documentation of doses occurred, or if dose amount or date of administration were not documented on a dose request. Patients with multiple requests were also excluded. For analysis of compliance defined by a 35-day administration interval, patients were excluded if documentation of at least 2 doses was not observed (Figure 3). 


\section{FIGURE 4 Sample Selection: Dose Projection} Formula Analysis

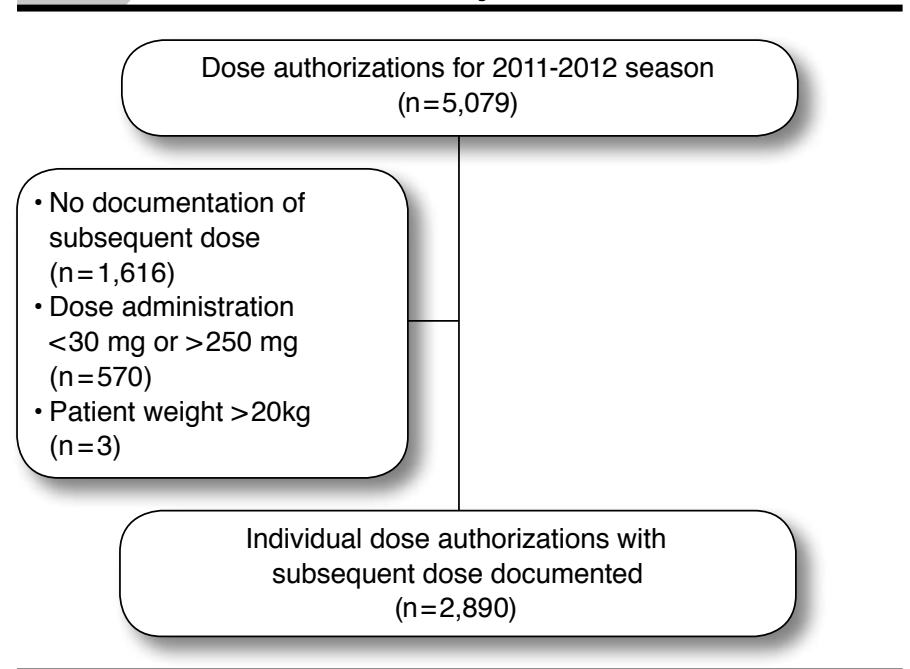

kg=kilograms; $m g=$ milligrams.

- Dose projection formula. All unique dose authorizations for the 2011-2012 season were reviewed for inclusion in the dose projection formula analysis. Dose authorizations were excluded if information was not available (i.e., last dose of the season; 31.8\%), if the documented dose administered was less than 30 milligrams (mg) or greater than $250 \mathrm{mg}$ (11.2\%), or if the weight of the infant was documented as greater than 20 kilograms (kg; 0.06\%). Exclusion criteria were based upon typical weight and dosing parameters for children $\leq 2$ years of age and maximum dosing limits set by NC Medicaid policy (Figure 4).

\section{Analysis}

Time to palivizumab coverage determination. Time to coverage determination for the 2010-2011 season was calculated as time elapsed from the date and time of the receipt of the PA request to the date and time that coverage determination was entered into the NC Medicaid PA documentation system. For requests received and/or reviewed prior to the start of claims processing for each season, submission and/or the coverage determination date and time were adjusted to the date when claims processing began for the season. An F-test to determine whether the 2 samples had equal variances was conducted using Microsoft Excel $(P<0.001)$. If the variances were equal, it was assumed that a Student's t-test could be used to compare means. Given unequal variances between the 2 samples used in this analysis, coverage determination times were compared between the 2 seasons using a 2-sample Student's t-test assuming unequal variance or a Welch's t-test to compare means. ${ }^{26}$
Palivizumab compliance. Compliance with palivizumab prophylaxis was defined in 2 ways. The actual number of injections documented as having been received was compared with the expected number to be documented based on the total number of doses approved. Providers were neither required nor incentivized to enter information for the final dose administered. We accounted for this in the expected number of doses to be documented. For example, beneficiaries who received a 5-dose approval in November were expected to have 4 of those doses documented in the web-based application. Patients who received a 2-dose approval in February were expected to have only 1 documented dose in the application. Any patient who received at least as many doses as expected was included in the analysis as being compliant. The second definition of compliance included subjects receiving at least 2 doses and was calculated as the proportion of subjects for whom documentation indicated receipt of all palivizumab doses within 35 days of the previous dose. We reported the proportion of patients who (a) received the total number of approved doses for the season, (b) received all but 1 of the total number of approved doses for the season, (c) received all doses within 35 days of the previous dose, and (d) received all approved doses within 35 days of the previous dose. The 35-day administration interval was selected based on the design of similar compliance analyses. ${ }^{19}$

Dose projection formula. The web-based PA application projected the amount of the next dose based on a standard formula that took into account a recent patient weight and the due date for the next dose. The due date was considered to be 30 days from the date the last dose was administered. Absolute and relative differences between projected and actual doses were calculated and reported using descriptive statistics. Projected and actual dose amounts for individual recipient doses were compared using a paired t-test. A sensitivity analysis, excluding dose differences of greater than 50\% to assess for potential bias introduced by system user error, was conducted. Correlation between relative difference and patient age on the date of administration were also assessed using a Pearson correlation coefficient. The projected dose formula is proprietary and therefore is not reported here.

\section{Results}

\section{Study Sample and Patient Characteristics}

During the 2010-2011 RSV season, 2,647 unique PA requests were submitted, and 2,366 unique requests were submitted during the 2011-2012 season.

For the 2011-2012 season, all 2,366 unique PA requests were included in the analysis of time to coverage determination: 1,374 were approved by the application, and 992 received medical review. Of the 2,647 unique requests identified for the 2010-2011 season, 414 were excluded because of missing fax and/or coverage decision dates or times, and 30 requests 


\section{TABLE 1 Beneficiary Characteristics ${ }^{\mathrm{a}}$}

\begin{tabular}{|c|c|c|c|}
\hline & $\begin{array}{l}2010-2011 \\
(\mathrm{n}=2,203) \\
\mathrm{n}(\%)\end{array}$ & $\begin{array}{l}2011-2012 \\
(\mathrm{n}=2,366) \\
\quad \mathrm{n}(\%)\end{array}$ & $P$ Value $^{\mathrm{b}}$ \\
\hline \multicolumn{4}{|l|}{ Sex } \\
\hline Male & $1,165 \quad(53.0)$ & $1,261 \quad(53.3)$ & \multirow{2}{*}{$<0.001$} \\
\hline Female & $1,033 \quad(47.0)$ & $1,105 \quad(46.7)$ & \\
\hline \multicolumn{4}{|l|}{ Race $^{c}$} \\
\hline Native American/Alaskan & $(1.8)$ & (1.6) & \multirow{6}{*}{$<0.001$} \\
\hline Asian & $14 \quad(0.6)$ & $(1.2)$ & \\
\hline African American & $920 \quad(41.9)$ & $968 \quad(40.9)$ & \\
\hline Pacific Islander & $(0.0)$ & $(0.1)$ & \\
\hline White & $979 \quad(44.5)$ & $1,127 \quad(47.6)$ & \\
\hline Unreported & $245 \quad(11.1)$ & $(8.5)$ & \\
\hline \multicolumn{4}{|l|}{$\overline{\text { Age }^{d}}$} \\
\hline $0-3$ months & $(2.9)$ & $(5.5)$ & \multirow{5}{*}{$<0.001$} \\
\hline 3-6 months & $416 \quad(18.9)$ & $499 \quad(21.1)$ & \\
\hline 6-12 months & $965 \quad(43.8)$ & $993 \quad(42.0)$ & \\
\hline 12-24 months & $620 \quad(28.1)$ & $638 \quad(27.0)$ & \\
\hline$>24$ months & $(6.3)$ & $(4.4)$ & \\
\hline Average (months) & 10.8 & 10.0 & $<0.001$ \\
\hline \multicolumn{4}{|c|}{$\begin{array}{l}\text { a Based on beneficiaries with prior approval requests for palivizumab. } \\
\text { bepresents the level of significance between the } 2 \text { seasons, using Pearson chi- } \\
\text { square tests for proportions and t-tests for means. }\end{array}$} \\
\hline \multicolumn{4}{|c|}{$\begin{array}{l}\text { 'Based on } n=2,198 \text { for the 2010-2011 season due to missing information in the NC } \\
\text { Medicaid eligibility database. } \\
\text { dCalculated as age at the end of each RSV season to account for beneficiaries born } \\
\text { during the season. } \\
N C=\text { North Carolina; RSV= respiratory syncytial virus. }\end{array}$} \\
\hline
\end{tabular}

were excluded because of ambiguity of medical review status; 2,203 requests were included in the analysis (Figure 2). Of the requests included in the analysis, 1,454 were approved by a technician or pharmacist, and 749 received medical review. Demographics of beneficiaries for whom requests were made are shown in Table 1.

For the 2011-2012 season, 1,578 palivizumab PA requests were approved. Of these, patients were excluded for not receiving at least 2 doses within the season $(n=128)$, when no documentation of doses occurred $(n=178)$ and when the dose amount or date of administration were not documented on a dose request $(n=34)$. Five recipients received duplicate case numbers; these were also excluded, leaving 1,233 requests included in the compliance analysis. For analysis of compliance defined by the 35-day administration interval, patients were excluded when documentation of at least 2 doses was not observed ( $n=142$; Figure 3).

During the 2011-2012 season, 5,079 unique dose authorizations were made. Dose authorizations were excluded when information was not available (i.e., last dose of the season; $\mathrm{n}=1,616$ ), when the documented dose administered was less than $30 \mathrm{mg}$ or greater than $250 \mathrm{mg}(\mathrm{n}=570)$, and when the weight of the infant was documented as greater than $20 \mathrm{~kg}$ $(\mathrm{n}=3)$. Analysis included 2,890 individual dose authorizations with documented subsequent dose administration (Figure 4).

\section{TABLE 2 Timeliness of Palivizumab} Coverage Determination

\begin{tabular}{|c|c|c|c|}
\hline & 2010-2011 & 2011-2012 & $\begin{array}{c}\text { Statistical } \\
\text { Difference } \\
(P)^{\mathrm{a}}\end{array}$ \\
\hline Total & $\mathrm{n}=2,203$ & $\mathrm{n}=2,366$ & \\
\hline $\begin{array}{l}\text { Mean days to coverage } \\
\text { determination (SD) }\end{array}$ & $8.5 \quad(15.4)$ & $4.8 \quad(9.3)$ & $<0.001$ \\
\hline Nonmedical review & $\mathrm{n}=1,454$ & $\mathrm{n}=1,374$ & \\
\hline $\begin{array}{l}\text { Mean days to coverage } \\
\text { determination (SD) }\end{array}$ & $3.4 \quad(14.2)$ & $0.0 \quad(0.0)$ & $<0.001$ \\
\hline Medical review & $\mathrm{n}=749$ & $\mathrm{n}=992$ & \\
\hline $\begin{array}{l}\text { Mean days to coverage } \\
\text { determination (SD) }\end{array}$ & $18.4 \quad(12.7)$ & $11.4 \quad(11.5)$ & $<0.001$ \\
\hline
\end{tabular}

aP value calculated using Student's t-test assuming unequal variances.

$S D=$ standard deviation .

\section{Time to Palivizumab Coverage Determination}

Time to palivizumab coverage determination decreased, on average, by 3.7 days ( 8.5 to 4.8 days; $P<0.001$ ) for the 20112012 season using the web-based PA application when compared with the traditional facsimile-based system used in the 2010-2011 season. Time to coverage determination for cases that did not require medical review decreased from 3.4 days during the 2010-2011 season to zero days in the 2011-2012 season $(P<0.001)$. Time to coverage determination for cases that required medical review decreased by 7 days, from 18.4 to 11.4 $(P<0.001$; Table 2, Figure 5). A multivariate regression analysis was also performed to assess for potential confounding by age of beneficiaries, which showed no significant difference attributed to the difference in age distributions between the 2 seasons.

\section{Palivizumab Compliance}

Of all palivizumab recipients who could have received at least 1 documentable dose $(n=1,233), 61.1 \%$ were fully compliant with all documentable doses, and $86.9 \%$ received all but 1 documentable dose. Of those who received at least 2 documented doses $(n=1,091), 62.8 \%$ received all doses within 35 days of the previous dose. Of recipients eligible for full season coverage, defined as 4 documentable doses $(n=769), 56.7 \%$ were fully compliant with all documentable doses; $81.1 \%$ were compliant with at least 3 of 4 documentable doses; and $56.9 \%$ received all documentable doses within 35 days of the previous dose. When compliance was defined as receipt of all documentable doses and receipt of all doses within 35-day intervals, $39.3 \%$ of all palivizumab recipients were considered compliant compared with $32.6 \%$ of recipients eligible for 5 doses (Table 3).

\section{Dose Projection Formula}

Projected doses and actual doses differed, on average, by $7.1 \mathrm{mg}$ or $8.6 \%$. When compared using a paired Student's t-test, mean 


\section{FIGURE 5 Timeliness of Palivizumab} Coverage Determination

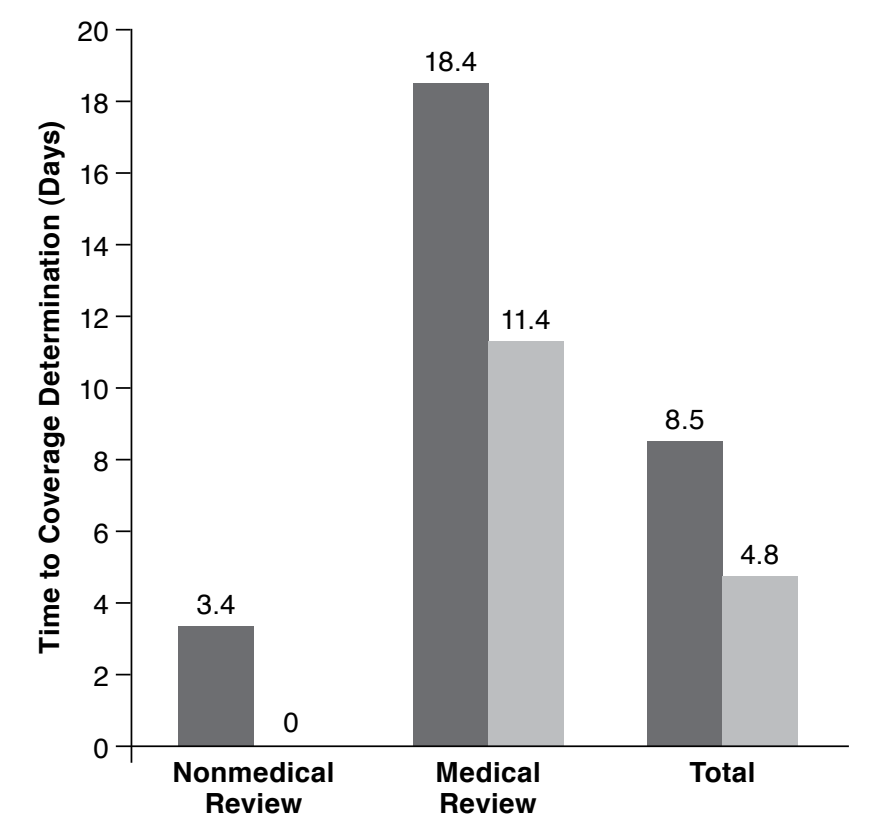

2010-2011 Facsimile-Based 2011-2012 Web-Based

projected and actual doses were significantly different (Table 4). In the sensitivity analysis that excluded projected and actual doses that differed by $\geq 50 \%$, we observed that some entries for patient weight and dose amount may have been entered erroneously for a given patient but fell within the inclusion criteria based on population values. Projected and actual doses did not vary significantly in the sensitivity analysis (Table 5). Relative difference was not correlated to patient age based on a Pearson correlation coefficient of -0.04 .

\section{Discussion}

This is the first known web-based PA application that has been utilized in the United States for palivizumab with the capability for automatic approval. Outcomes of this study - including timeliness of coverage determination, compliance, and accuracy of the dose projection formula-were selected based on features designed to improve the PA process. Improving this process is expected to ensure timely receipt of palivizumab for high risk infants and children at the start of and throughout the RSV season as well as reduce wastage of this costly medication.

Time to coverage determination for palivizumab was significantly reduced with implementation of the web-based application. This was due, mostly, to the large number of cases eligible for instant approval based on the diagnosis for the request. Ability to further reduce time to coverage determination was

\section{TABLE 3 Compliance with Palivizumab} Regimen Among 2011-2012 Season Recipients

\begin{tabular}{|c|c|c|}
\hline & $\begin{array}{l}\text { Total } \\
\text { Recipients } \\
2011-2012\end{array}$ & $\begin{array}{c}\text { Recipients } \\
\text { Eligible for } \\
\text { Full 2011-2012 } \\
\text { Season }^{\mathrm{a}}\end{array}$ \\
\hline $\begin{array}{l}\text { Compliance defined by number } \\
\text { of doses received }\end{array}$ & $\mathrm{n}=1,233$ & $\mathrm{n}=769$ \\
\hline Received all documentable doses ${ }^{\mathrm{b}}$ (n) & $61.1 \% \quad(753)$ & $56.7 \% \quad(435)$ \\
\hline $\begin{array}{l}\text { Received all but one documentable } \\
\text { doses (n) }\end{array}$ & $86.9 \%(1,076)$ & $81.1 \% \quad(626)$ \\
\hline $\begin{array}{l}\text { Compliance defined by interval between } \\
\text { doses }\end{array}$ & $\mathrm{n}=1,091$ & $\mathrm{n}=708$ \\
\hline $\begin{array}{l}\text { Received all doses within } 35 \text { days of } \\
\text { previous dose }\end{array}$ & $62.8 \% \quad(685)$ & $56.9 \% \quad(403)$ \\
\hline $\begin{array}{l}\text { Compliance defined by number of doses } \\
\text { received and interval between doses }\end{array}$ & $\mathrm{n}=1,091$ & $\mathrm{n}=769$ \\
\hline $\begin{array}{l}\text { Received all documentable doses and } \\
\text { received all doses within } 35 \text { days of } \\
\text { the previous dose }\end{array}$ & $39.3 \% \quad(429)$ & $32.6 \% \quad(231)$ \\
\hline \multicolumn{3}{|c|}{$\begin{array}{l}{ }^{a} \text { Full season }=5 \text { doses. } \\
{ }^{2} \text { Number of documentable doses=number of total approved doses minus } 1 \text { as } \\
\text { providers were not required to document last dose information. }\end{array}$} \\
\hline
\end{tabular}

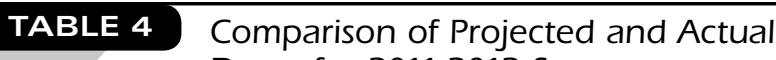
Doses for 2011-2012 Season

\begin{tabular}{l|c|c|c|c|c}
\hline & $\begin{array}{c}\text { Projected } \\
\text { Doses } \\
(\mathbf{n = 2 , 8 9 0 )}\end{array}$ & $\begin{array}{c}\text { Actual } \\
\text { Doses } \\
(\mathbf{n = 2 , 8 9 0 )}\end{array}$ & $\begin{array}{c}\text { Absolute } \\
\text { Difference }\end{array}$ & $\begin{array}{c}\text { Relative } \\
\text { Difference } \\
(\%)\end{array}$ & $\begin{array}{c}\text { Statistical } \\
\text { Difference } \\
(\boldsymbol{P}))^{\mathrm{a}}\end{array}$ \\
\hline Mean (mg) & 92.4 & 91.6 & 7.1 & 8.6 & 0.001 \\
\hline Range (mg) & $28.2-231.3$ & $30.0-215.0$ & $0-152.1$ & $0.0-395.0$ & - \\
\hline $\begin{array}{l}95 \% \text { confidence } \\
\text { interval (mg) }\end{array}$ & - & - & $6.8-7.5$ & $8.0-10.0$ & - \\
\hline
\end{tabular}

ap value calculated using paired Student's t-test.

$m g=$ milligrams.

\begin{tabular}{|c|c|c|c|c|c|}
\hline & $\begin{array}{c}\text { Projected } \\
\text { Doses } \\
(\mathbf{n}=2,850)\end{array}$ & $\begin{array}{c}\text { Actual } \\
\text { Doses } \\
(\mathbf{n}=2,850) \\
\end{array}$ & $\begin{array}{c}\text { Absolute } \\
\text { Difference } \\
\end{array}$ & $\begin{array}{c}\text { Relative } \\
\text { Difference } \\
(\%)\end{array}$ & $\begin{array}{l}\text { Statistical } \\
\text { Difference } \\
(P)^{\mathrm{b}} \\
\end{array}$ \\
\hline Mean (mg) & 91.8 & 91.9 & 6.3 & 7.1 & 0.451 \\
\hline Range (mg) & $28.2-231.3$ & $30.0-215.0$ & $0-75.7$ & $0-49$ & - \\
\hline $\begin{array}{l}95 \% \\
\text { confidence } \\
\text { interval (mg) }\end{array}$ & - & - & $6.0-6.5$ & $6.7-7.3$ & - \\
\hline \multicolumn{6}{|c|}{$\begin{array}{l}\text { a Sensitivity analysis sample excluded all doses with } \geq 50 \% \text { difference from projected } \\
\text { dose. } \\
\text { bP value calculated using paired Student's t-test. } \\
\text { mg=milligrams. }\end{array}$} \\
\hline
\end{tabular}




\section{Evaluation of a Novel Web-Based Prior Approval Application for Palivizumab Prophylaxis of Respiratory Syncytial Virus in a State Medicaid Program}

limited because many providers did not utilize the application's upload feature to attach documents that would justify medical necessity. Providers instead continued to use facsimile submission for supporting documentation, which required medical reviewer personnel to manually match these documents to requests in the web-based application. Additionally, supporting documentation submitted was often not sufficient to justify medical necessity and frequently required multiple requests to providers for additional information. Further reducing time to coverage determination may streamline the administrative burden of the program and allow infants at high risk of serious respiratory tract infections from RSV to receive palivizumab sooner.

Observed compliance rates in this study were slightly lower when compared with compliance rates reported for Medicaid recipients in the Palivizumab Outcomes Registry, defined as the number of palivizumab doses received compared with expected number of doses (61.1\% vs. $76 \%$ ). When compliance was defined by receipt of all doses within 35 days of the previous dose, we observed a slightly higher rate of compliance in 2011-2012 NC Medicaid recipients than those reported in the Palivizumab Outcomes Registry (62.8\% vs. 61\%). ${ }^{15}$ Monthly injections are recommended during the RSV season based on the 20-day half-life of palivizumab. ${ }^{7}$ Thus, compliance with the recommended regimen is needed to maintain serum concentration sufficient to provide prophylaxis throughout the RSV season. Falling serum concentrations as a result of noncompliance can result in hospitalization and wasted expense on previously administered doses. The web-based application evaluated in this study was not initially designed to affect either definition of compliance but rather to provide a means to assess compliance at baseline and have the capability to make system improvements moving forward that may reduce gaps in prophylaxis.

The dose projection formula used within the application appears to be accurate. Given the linear dose projection formula, we suspected that the relative difference in projected and actual doses may vary depending on patient age because pediatric growth curves are not linear between 0 and 2 years of age. However, we did not observe this effect. An accurate dose projection formula is expected to decrease dispensing of excess palivizumab and therefore costs associated with the wastage of the excess medication.

In a recent white paper published by URAC on patient management as a critical component of specialty pharmacy, it was noted that health plans desire compliance and optimal dosage programs more commonly than other therapy management programs. ${ }^{27}$ Although this paper was published after the implementation of the web-based palivizumab PA application for NC Medicaid, it is notable that concerns about optimal dosage and adherence were among the top reasons of NC Medicaid to consider a different way of conducting PA.

\section{Implications for Practice}

This study has implications for future PA initiatives for palivizumab. While overall timeliness of palivizumab coverage determination decreased significantly because of the instant approval capability of the web-based application, more specific instructions for both the type and submission method of supporting documentation sufficient to justify medical necessity should be included. The compliance rates, based on the interval between doses that were identified through this evaluation, suggest that the window for the e-mail alerts should be shortened. For the upcoming season, the application will e-mail providers beginning at 28 days from the last dose request date. Given the number of entries excluded based on our exclusion criteria for the dose projection algorithm analysis, data verification algorithms could be used in the application to protect accuracy of the dose projection formula from erroneously entered values. For instance, dose amounts and patient weights could be compared with population norms and perhaps previous entries for a given patient.

\section{Implications for Research}

The findings from this study have implications for future research. Overall, the cost to NC Medicaid for palivizumab claims decreased by just over $\$ 3$ million from the 2010-2011 season compared with the 2011-2012 season. Interestingly, the average cost per recipient of palivizumab to NC Medicaid was almost identical between the 2 seasons. Future modifications to the application that address accuracy of user entries may decrease wastage, reducing average cost per recipient. The number of recipients with claims for palivizumab decreased by 300 recipients or $20 \%$. The number of requests also decreased by approximately 300 , or $11 \%$. The proportion of palivizumab requests approved decreased from $72.8 \%$ in the 2010-2011 season to $66.7 \%$ in the $2011-2012$ season. It is unclear whether the decrease in approved requests and recipients of palivizumab are due to decreased inappropriate requests for palivizumab or decreased requests for recipients with legitimate medical necessity. Future research should seek to determine legitimacy of requests and the impact of a web-based application. Additionally, this study was not designed to assess health outcomes related to compliance. These outcomes should be targets for future research

\section{Limitations}

The quality of the 2011-2012 data used for the compliance and dose projection analyses may have been affected by the accuracy of data entry by application users. We attempted to control for potentially erroneously entered values in our exclusion criteria; however, values may have been included in the sample that would have appeared appropriate for the population but inappropriate for a particular patient. In order to correct for bias introduced by this error, we conducted a 


\section{Evaluation of a Novel Web-Based Prior Approval Application for Palivizumab Prophylaxis of Respiratory Syncytial Virus in a State Medicaid Program}

sensitivity analysis for the dose projection formula evaluation. We were unable to assess for bias because of differences in the distribution of the population by diagnosis for each season due to poor image quality of requests submitted by facsimile. We included a multivariate analysis to account for bias because of distribution of age of beneficiaries receiving palivizumab for both seasons. Additionally, we relied on a date and time stamp on each PA request from the receiving fax machine as the date received. These machines may not have been calibrated accurately, introducing systematic error. Several PA requests in both the 2010-2011 and 2011-2012 seasons were submitted prior to the start of the RSV season. Because reviewers did not necessarily review early requests when received, we used the date that claims processing could begin for palivizumab as the date received and/or decision date for any preceding the date claims processing began. We did not include the final dose of palivizumab for any beneficiaries in the analyses because providers were neither required nor incentivized to enter information about the last dose of palivizumab administered, and palivizumab claims data has limitations discussed elsewhere. ${ }^{24}$ This potential limitation was addressed by consistently omitting the last dose for each beneficiary in our compliance calculations.

\section{Conclusions}

The 2011-2012 web-based PA application was associated with improved timeliness of palivizumab coverage determination when compared with the 2010-2011 facsmile-based system. Observed compliance rates for NC Medicaid recipients were slightly lower than those reported in the literature when defined by the number of doses received but were higher when defined by the interval between doses. The dose projection formula used for the web-based application appears to be accurate for infants $0-2$ years of age.

\section{Authors}

KRISTIN LUNDEEN, PharmD, is Network Pharmacist; TIMOTHY O'BRIEN, MSc, is Data Analyst; and STEVEN WEGNER, MD, JD, is President, AccessCare, Morrisville, North Carolina. TRISTA PFEIFFENBERGER, PharmD, MS, is Assistant Director, Pharmacy Programs, Community Care of North Carolina, Raleigh, North Carolina; JULIE JACOBSON VANN, PhD, MS, RN, is Senior Researcher, American Institutes for Research, Chapel Hill, North Carolina; and CHARLENE SAMPSON, RPh, is Pharmacist, Outpatient Pharmacy Program, NC Division of Health and Human Services, Division of Medical Assistance, Raleigh, North Carolina.

AUTHOR CORRESPONDENCE: Kristin Lundeen, PharmD, AccessCare, 3000 Aerial Center Pkwy., Ste. 101, Morrisville, NC 27560. Tel.: 919.228.2286; Fax: 919.468.8573;

E-mail:klundeen@ncaccesscare.org.

\section{DISCLOSURES}

There was no external funding for this study, and the authors report no conflict of interest associated with this study. Concept and design were performed by all authors. Data were collected by Lundeen. Data were interpreted by Lundeen, O'Brien, Pfeiffenberger, and Jacobson Vann. Writing of the manuscript was performed by Lundeen, Pfeiffenberger, and Jacobson Vann. The manuscript was revised by all authors. The authors wish to acknowledge Greg Moyer, Matthew Caldwell, and Hannah Wigmore for assistance with data collection and Troy Trygstad, PharmD, PhD, for his assistance with manuscript review.

\section{REFERENCES}

1. Express Scripts Inc. 2011 drug trend report. April 2012; 74. Available at: http://www.express-scripts.com/research/research/dtr/archive/2012/dtrFinal.pdf. Accessed February 18, 2013.

2. Centers for Disease Control and Prevention. Respiratory syncytial virus (RSV): infection and incidence. January 25, 2010. Available at: http://www. cdc.gov/rsv/about/infection.html. Accessed February 18, 2013.

3. Centers for Disease Control and Prevention. Respiratory syncytial virus activity-United States, July 2007-December 2008. MMWR Morb Mortal Wkly Rep. 2008;57(50):1355-58. Available at: http://www.cdc.gov/mmwr/preview/mmwrhtml/mm5750a3.htm. Accessed February 18, 2013.

4. Boyce TG, Mellen BG, Mitchel EF Jr, Wright PF, Griffin MR. Rates of hospitalization for respiratory syncytial virus infection among children in Medicaid. J Pediatr. 2000;137(6):865-70.

5. Shay DK, Holman RC, Newman RD, Liu LL, Stout JW, Anderson LJ. Bronchiolitis-associated hospitalizations among US children, 1980-1996. JAMA. 1999;282(15):1440-46. Available at: http://jama.jamanetwork.com/ article.aspx?articleid=192009. Accessed February 18, 2013.

6. Leader S, Kohlhase K. Recent trends in severe respiratory syncytial virus (RSV) among US infants, 1997 to 2000. J Pediatr. 2003;143(5 Suppl):S127-S132

7. Synagis (palivizumab) for intramuscular injection. MedImmune. April 2011. Available at: http://www.medimmune.com/pdf/products/synagis_ pi.pdf. Accessed February 18, 2013

8. Winterstein AG, Hampp C, Saidi A. Effectiveness of palivizumab prophylaxis in infants and children in Florida. Pharmacoepidemiol Drug Saf. 2012;21(1):53-60

9. Hampp C, Kauf TL, Saidi AS, Winterstein AG. Cost-effectiveness of respiratory syncytial virus prophylaxis in various indications. Arch Pediatr Adolesc Med. 2011;165(6):492-505.

10. Wegner S, Vann JJ, Liu G, et al. Direct cost analyses of palivizumab treatment in a cohort of at-risk children: evidence from the North Carolina Medicaid program. Pediatrics. 2004;114(6):1612-19.

11. Elhassan NO, Sorbero ME, Hall CB, Stevens TP, Dick AW. Costeffectiveness analysis of palivizumab in premature infants without chronic lung disease. Arch Pediatr Adolesc Med. 2006;160(10):1070-76.

12. Fariña D, Rodriguez SP, Bauer G, et al. Respiratory syncytial virus prophylaxis: cost-effective analysis in Argentina. Pediatr Infect Dis J. 2002;21(4):287-91.

13. Yount LE, Mahle WT. Economic analysis of palivizumab in infants with congenital heart disease. Pediatrics. 2004;114(6):1606-11

14. Kamal-Bahl S, Doshi J, Campbell J. Economic analyses of respiratory syncytial virus immunoprophylaxis in high-risk infants: a systematic review. Arch Pediatr Adolesc Med. 2002;156(10):1034-41.

15. Frogel M, Nerwen C, Cohen A, et al. Prevention of hospitalization due to respiratory syncytial virus: results from the Palivizumab Outcomes Registry. J Perinatol. 2008;28(7):511-17. 


\section{Evaluation of a Novel Web-Based Prior Approval Application for Palivizumab Prophylaxis of Respiratory Syncytial Virus in a State Medicaid Program}

16. Joffe S, Ray GT, Escobar GJ, Black SB, Lieu TA. Cost-effectiveness of respiratory syncytial virus prophylaxis among preterm infants. Pediatrics. 1999;104(3 Pt 1):419-27.

17. Diehl JL, Daw JR, Coley KC, Rayburg R. Medical utilization associated with palivizumab compliance in a commercial and managed Medicaid health plan. J Manag Care Pharm. 2010;16(1):23-31. Available at: http://www. amcp.org/data/jmcp/23-31.pdf.

18. No authors listed. Palivizumab, a humanized respiratory syncytial virus monoclonal antibody, reduces hospitalization from respiratory syncytial virus infection in high-risk infants. The IMpact-RSV Study Group. Pediatrics. 1998;102(3 Pt 1):531-37.

19. Frogel M, Stewart DL, Hoopes M, Fernandes AW, Mahadevia PJ. A systematic review of compliance with palivizumab administration for RSV immunoprophylaxis. J Manag Care Pharm. 2010;16(1):46-58. Available at: http://www.amcp.org/data/jmcp/46-58.pdf.

20. Hampp C, Saidi AS, Winterstein AG. Palivizumab utilization and compliance: trends in respiratory syncytial virus prophylaxis in Florida. J Pediatr. 2010;156(6):953-59.

21. Hand IL, Noble L, Geiss D, Shotkin A. Respiratory syncytial virus immunoprophylaxis in an urban population: a comparison of delivery strategies and outcomes. Pediatr Infect Dis J. 2008;27(2):175-76.
22. Paul DA, Leef KH, Chidekel A, et al. Home delivery of palivizumab: outcomes and compliance in regional preterm infants. Del Med J. 2002;74(1):11-15.

23. Pignotti MS, Indolfi G, Donzelli G. Factors impacting compliance with palivizumab prophylaxis. Pediatr Infect Dis J. 2004;23(2):186-87.

24. Committee on Infectious Diseases. From the American Academy of Pediatrics: Policy statements-modified recommendations for use of palivizumab for prevention of respiratory syncytial virus infections. Pediatrics. 2009;124(6):169-701

25. Jacobson Vann J, Feaganes J, Wegner S. Reliability of Medicaid claims versus medical record data: in a cost analysis of palivizumab. Pharmacoeconomics. 2007;25(9):793-800.

26. Welch BL. The generalisation of student's problems when several different population variances are involved. Biometrika. 1947;34(1-2):23-35

27. URAC Pharmacy Quality Management. The patient-centered outgrowth of specialty pharmacy: why patient management strategies are critical to 21st century providers. URAC Specialty Pharmacy White Paper. 2011. Available at: https://www.urac.org/Whitepaper/PQM-Specialty_Pharmacy. pdf. Accessed February 18, 2013. 